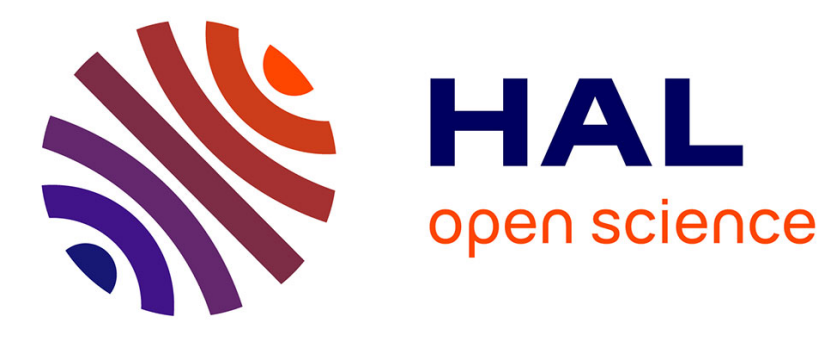

\title{
Education status among orphans and non-orphans in communities affected by AIDS, in Tanzania and Burkina Faso
}

Marie-Laure Kurzinger, Joel Pagnier, James G. Kahn, Rachel Hampshire, Timothy Wakabi, Timothy Dye

\section{To cite this version:}

Marie-Laure Kurzinger, Joel Pagnier, James G. Kahn, Rachel Hampshire, Timothy Wakabi, et al.. Education status among orphans and non-orphans in communities affected by AIDS, in Tanzania and Burkina Faso. AIDS Care, 2008, 20 (06), pp.726-732. 10.1080/09540120701693958 . hal-00513433

\section{HAL Id: hal-00513433 https://hal.science/hal-00513433}

Submitted on 1 Sep 2010

HAL is a multi-disciplinary open access archive for the deposit and dissemination of scientific research documents, whether they are published or not. The documents may come from teaching and research institutions in France or abroad, or from public or private research centers.
L'archive ouverte pluridisciplinaire HAL, est destinée au dépôt et à la diffusion de documents scientifiques de niveau recherche, publiés ou non, émanant des établissements d'enseignement et de recherche français ou étrangers, des laboratoires publics ou privés. 

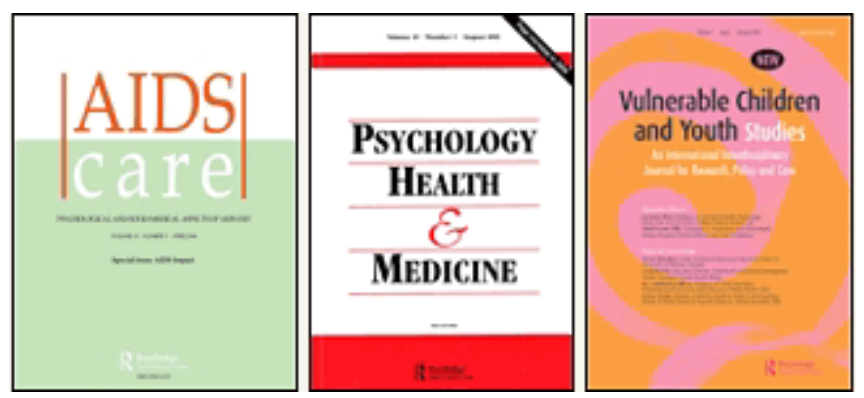

Education status among orphans and non-orphans in communities affected by AIDS, in Tanzania and Burkina Faso

\begin{tabular}{|r|l|}
\hline Journal: & $\begin{array}{l}\text { AIDS Care - Psychology, Health \& Medicine - Vulnerable Children } \\
\text { and Youth Studies }\end{array}$ \\
\hline Manuscript ID: & AC-2006-12-0297.R1 \\
\hline Journal Selection: & AIDS Care \\
\hline Keywords: & orphans, burkina faso, tanzania, AIDS, education \\
\hline \multicolumn{2}{|l}{} \\
\hline
\end{tabular}

\section{今 scholaroNE" \\ Manuscript Central}


Education status among orphans and non-orphans in communities affected by AIDS, in Tanzania and Burkina Faso 


\section{Abstract}

The AIDS pandemic has created an estimated 15 million orphans, who may face elevated risk of poor health and social outcomes. This paper compares orphans and non orphans regarding educational status and delay using data collected in 3 lowincome communities affected by AIDS in Tanzania and Burkina Faso. Orphans were significantly more likely not to attend school than were non orphans and also to be delayed when in school, though after controlling for confounders the risk was borderline and non-significant. Multivariate analysis indicates that variables such as age, religion, family of origin, the relation between the child and the head of household, and the dependency ratio of the household better explain differences in education than does orphan status. This study suggests, therefore, that orphans' educational status is relatively equivalent to non orphans perhaps as a result of family based or community program safety nets.

Keywords: Orphans, Children, Education, Burkina Faso, Tanzania, HIV, AIDS, Logistic Regression. 


\section{Introduction}

The AIDS pandemic has created millions of orphans, a trend envisioned to continue for the foreseeable future (Foster and Williamson 2000). From 2001 to 2003, the estimated global number of AIDS orphans increased from 11.5 million to 15 million. (UNICEF, UNAIDS, USAID, 2004). This magnitude of orphans poses a long-term threat to future stability and development, especially in Sub-Saharan Africa with the highest levels of HIV prevalence in the world. In 2005, the estimated prevalence of adults (15-49 years) living with HIV/AIDS was $2 \%$ in Burkina Faso and $6.5 \%$ in Tanzania. Further, $10 \%$ of children were orphans in Burkina Faso and $12 \%$ in Tanzania (UNICEF, 2006).

Orphans may be disadvantaged in numerous ways, according to several recent assessments (Andrews et al, 2006; UNICEF, UNAIDS, USAID, 2004; UNICEF, 2003; Foster and Williamson 2000;). In terms of education, orphans have often been reported to be less likely enrolled in school (Foster \& Williamson, 2000; USAID, 2004), though somewhat inconclusively Studies often, however, use inconsistent methods to control for potential confounders. Analyses which consider the impact of other variables are needed, such as age and gender of the child, household characteristics (size, socio-economic status, dependency ratio) (Ainsworth \& Filmer, 2002; Bicego et al., 2003), head of the household characteristics (closeness of the relationship with the child, gender) (Ainsworth \& Semali, 2000; Ainsworth \& Filmer, 2002; Bicego et al., 2003; Bishai et al., 2003; Case et al., 2003; Lindblade et al., 2003) and geographic variables (urban/rural settings, regions, countries) (Ainsworth 
\& Filmer, 2002; Bicego et al., 2003). Further, the condition of orphans may vary by geographic setting, due to differing economic conditions and cultural practices (Foster and Williamson 2000). Finally programs specifically targeting the educational and social needs have proliferated throughout Africa in recent years with unclear impact to date. At least one prior study in this region (Pagnier et al, in press) demonstrates that once controlling for sociodemographic correlates, differences no longer exist in school enrollment and school delay in an urban region of Burkina Faso. Thus, a better understanding of how orphan conditions vary is needed, in order for policy makers to better promote, change and improve child well-being in impoverished communities.

In the context of community strengthening, national and local authorities of Burkina Faso and Tanzania, with funding from The Abbott Fund and technical support from Axios ${ }^{1}$, started implementing in 2001-2002 the Step Forward program on orphans and vulnerable children (OVC) in HIV/AIDS affected areas. Step Forward is a multisectoral program that works through a combination of community support (information andeducationactivities, legal support, renovation of school, equipment, and local capacity building) as well as direct support to OVC (food, uniforms, lamps, school fees for schools, health care andtreatment). The program aims at improving the individual living conditions of OVC and simultaneously improving the community environment where they live.

Before starting Step Forward, mapping exercises were conducted in each selected geographic area. These mappings were intended to serve programmatic goals: for

\footnotetext{
${ }^{1}$ Founded in 1997, Axios is a global consultancy improving health systems and quality of care in developing countries through healthcare philanthropy and drug donation program management
} 
community mobilization, and to identify and locate all orphans, vulnerable children, and non-OVC eligible for direct support. The research objectives were to establish pre-program baseline educational and health status among orphans and non orphans living in the selected areas, and to assess to what extent orphans are disadvantaged relative to non orphan with regard to these basic needs for personal and national development.

\section{Materials and Methods}

A "mapping exercise" (i.e., a comprehensive sample and cross-sectional survey) was conducted to identify OVC and their living conditions (details below). In each district selected by needs assessments data were collected on paper questionnaires and were checked, double entered and checked for consistency with descriptive statistics. Corrections were made through reconciliation with physical questionnaires. Data were analyzed using the SAS® software version 9.1 .

The "mapping exercise" refers to the social mapping whereby village leaders, community members, district council officials and project staff collaborate in the process of identifying all children of the targeted community, including orphans, vulnerable children and non-OVC. This community mapping permitted specification of comprehensive samples (Michigan State University, 1999).

Three such mappings were conducted in 2003: one in Tanzania (in rural setting, Maramba ward of Muheza District) and two in Burkina Faso (in a rural setting of Kongoussi and in a peri-urban setting, Kiri-Sakabi). The study sample included 
11,392 and 11,856 children aged 0 to 18 years old in Tanzania and Burkina Faso, respectively, representing 3,892 and 3,262 households.

The respondent in each household was the primary caregiver and in case of her/his absence the household head. This respondent provided the required information for all eligible children (i.e. children under 18 living in the household).

The mapping exercise collected data on household characteristics and sociodemographics, as well as information on educational and health status of the children. Detail on key variables is provided in the next section.

\section{Variables and statistical analysis}

Outcomes were defined as follows:

(1) School enrollment: whether the child was declared to be currently going to school or not; the question asked was: "The child is/has: 1=Going to school, 2=Dropped out, 3=Never been to school"

(2) Proper level: if the child was going to school, the current level was compared to the recommended level for the age of the child. If the current level was lower than the recommended one, then the child was classified as not being at proper level. This variable could reflect late school entry and/or interruption:

Several potential confounders were considered:

(1) Age of the child, in two categories: 6-11, 12-18;

(2) Gender of the child; 
(3) Religion of the child, in two categories: Christians and Muslims

(4) Family of origin, i.e., if the child is living in the family of origin or not;

(5) Gender of the head of household;

(6) Relationship between the child and the head of the household: the head of household is one of the child's parents or another relative/non relative, or one of the grand-parents;

(7) Household child/adult (dependency) ratio, which is calculated by dividing the number of children (under 18 years old) by the number of adults (19 years and above) within a household. This ratio, expected to show the burden of child care by household, was divided into two categories, $\leq 1,>1$. Households with a ratio $\leq 1$ have more adults than children.

The predictor was the orphan status. An orphan was defined as a child under the age of 18 who has lost one or both parents, corresponding to the recommended definition (UNAIDS, UNICEF, USAID, 2004). The non orphan category was defined as a non-OVC. In fact, to better focus on the comparison between orphans and non orphans, "vulnerable" children were excluded because they represented a heterogeneous category subjectively defined by the interviewer.

Stepwise logistical regression was used to analyze the relationship between orphan status and education. Bivariate (unadjusted) models were performed to assess the relationship between the outcome and the predictor (orphan status) and all potential confounders separately. Potential confounders which were found to be independently at at least marginally-associated $(p<0.10)$ with the likelihood of being an orphan and with the outcome were included in multivariate results, to examine 
how the magnitude and statistical significance of the orphan status coefficient changes with introduction of these confounders. The magnitude of association is demonstrated by Odds Ratios (OR) while statistical significance is noted through calculation of $95 \%$ confidence intervals $(95 \% \mathrm{Cl})$ around ORs. When appropriate, adjusted ORs are used to control for confounding effects.

\section{Results}

In total, the sub-population of orphans and non orphans aged 6-18 represented 4931 and 4835 children in Tanzania and Burkina-Faso, respectively. In total, $64.8 \%$ of the orphans were not going to school in Burkina Faso versus $27.3 \%$ in Tanzania (Table 1). No significant difference was observed in Tanzania between orphans and non orphans regarding school enrollment or school delay. In Burkina Faso, however, orphans were significantly more likely not to attend school when compared with non orphans (OR=1.21; 95\% Cl: 1.03, 1.42), and among those children who were going to school, orphans were significantly more likely not to be at the proper school level for their age (OR: $1.40 ; 95 \% \mathrm{Cl}: 1.05,1.87)$.

\section{Location of table 1}

Table 2 presents bivariate associations (and 90\% confidence intervals) between potential confounding variables and the main outcomes of interest in the Burkina Faso sample only because in Tanzania results were non significant. Orphans were more than twice as likely as other children to be older (12-18 years). There was no significant difference between males and females in terms of orphanhood. Religion 
and orphanhood were significantly associated $(\mathrm{OR}=1.4 ; 90 \% \mathrm{Cl}: 1.23,1.60)$. Orphans were more likely to live in female headed household than non orphans $(\mathrm{OR}=14.8 ; 90 \% \mathrm{Cl}: 12.2,17.9)$. Family of origin and relationship between the child and the head of the household were significantly associated with orphanhood. There was no association between the dependency ratio and the orphanhood.

12-18 year old children had 1.5 more risk of not going to school than children age 611 years. Female were also more at risk of not going to school $(\mathrm{OR}=1.2 ; 90 \% \mathrm{Cl}$ : $1.09,1.33)$. Christians were more likely to go to school than Muslims. For the children not living in their family of origin, OR was equal to $1.2(90 \% \mathrm{Cl}: 1.03,1.49)$. Children living with their grand-parents were significantly more likely to go to school than those living with their parents or other relatives. Children living in families where the dependency ratio is higher than 1 were at a significantly higher risk of not going to school (OR=1.13; $90 \% \mathrm{Cl}: 1.01,1.27)$.

Age was associated with not being at proper educational level $(\mathrm{OR}=24.8 ; 90 \% \mathrm{Cl}$ : $17.41,35.24)$. Religion was also associated with the fact of being at proper level or not; Christians were more likely not to be at proper level (OR=1.3; $\mathrm{Cl}: 1.09,1.52)$. Children living in female headed household were more likely to be in delay at school. Children not living in their families of origin were more likely to experience delay at school. The other variables such as sex of the child, relationship of the child to the head of the household, dependency ratio and perceived health were not found to be associated with a delay in school.

Location of table 2 
Therefore, once controlling for other social and demographic factors, orphans in Burkina Faso were not more likely than other children to experience delay or nonenrollment. Although for school enrollment the OR was borderline significant $(\mathrm{OR}=1.19 ; 95 \% \mathrm{Cl}=0.99,1.41)$.

\section{Location of table 3}

Other studies have focused on different types of orphans (Ainsworth \& Filmer, 2002; Bicego et al., 2003; Case et al., 2003, Lindblade et al., 2003). Double orphans are defined as children having lost both parents, paternal orphans as children having lost their father and maternal orphans their mother. The sample size allowed us to analyze potential differences between the 4 groups of children in terms of school enrollment. We applied the same methodology as for the previous analysis but defining the orphan status into the 4 following categories: double orphans, maternal orphans, paternal orphans and non orphans as the group of reference. The Tanzania sample showed no difference in terms of school enrollment by type of orphans. On the other hand, for the Burkina Faso sample, even after adjustment on confounders, paternal orphans were at higher risk of not going to school compared to non orphans $(\mathrm{OR}=1.7 ; 95 \% \mathrm{Cl}: 1.27,2.23)$.

\section{Discussion}

The differences observed in schooling rates between the two countries are distinct and likely reflect the overall income levels and policies on universal primary education. Data consistently shows significant differences in educational attendance between Tanzania and Burkina Faso, with the former having far higher rates of attendance particularly in rural areas and particularly at the primary school levels 
(see INSD 2004; NBS 2005). The difference in various fees applied to school attendance (e.g. tuition, uniforms, textbooks, other fees) is considerable, with Tanzania offering fee-free education while Burkina Faso implements several different fee structures (see Bentaouett 2006, for example).

After adjustment for potential confounders in both countries, however, we found no significant differences remained between orphans and non orphans in terms of education status, as measured by declared school enrollment and school delay. The relationship between orphan status and educational enrollment in Burkina Faso approaches statistical significance, perhaps indicating a positive impact of family and community mobilization around orphans. Our findings suggest that either other social and demographic variables affect more educational enrollment and delay than does orphanhood, or perhaps that community's efforts to compensate for challenges facing orphans have mediated the potentially negative impact of orphanhood on educational status (for example, see Nyamukapa and Gregson 2005) .

Findings in the literature show that orphans are less likely to be enrolled or at their proper educational level than non orphans of the same age, and double orphans are at particular disadvantage (Bicego et al., 2003). Our model shows that high child/adults ratio (>1) seems to be associated with a higher risk of not attending school. If we consider the child/adult ratio as an approximation of the dependency ratio, it could be an indication that dependency is associated with school enrollment. Studies have shown that poverty rather than orphan status was the primary determinant of school enrollment (Ainsworth \& Filmer, 2002). Religion is associated with school enrollment as well. For the Burkina Faso sites, while Christians are more 
likely to be orphans, perhaps reflecting the epidemiology of HIV infection in Africa (e.g., see Gray 2004), Christians also have higher likelihood of attending formal school than Muslims. The result could be explained by the fact that Muslim children often attend non-formal education (i.e. Islamic school). Children living in female headed households and children not living in their family of origin are less likely to attend school and to be at proper level which suggests that the household environment may better explain school differences. In female headed household, which could experience economic difficulties, school fees, uniforms, domestic responsibilities or paid work could be a barrier to education. Further, it's possible that there may also be discimination in terms of not providing education for children not living in their family of origin (e.g. Manasch et al 2007).

A number of limitations must be considered in the interpretation of our findings. We did not measure and thus lacked economic indicators at the household level. The school enrollment status and grade were self-reported; determination from written records would have been more definitive (Orazem \& Gunnarsson, 2003). Further, street children and children in institutions were not included. Respondents may also have misreported the survival status of the biological parents. Children whose parents are alive but absent (such a working/living in Ivory Coast) are often considered as orphans.

Our findings overall suggest that orphans and non orphans are not significantly different in terms of educational status in the surveyed communities. However three points need to be underlined. First, other characteristics, rather than orphan status, appear to be more important determinants of educational attendance and 
achievement. This finding is consistent with other studies (Ainsworth \& Filmer, 2002; Case et al., 2003) which showed the importance of other sociodemographic variables. Thus a more subtle identification of at-risk (of education enrollment and achievement) children should be possible. Further, it is possible that a stronger relationship has been moderated by community programs or family mobilization around orphans. Several programs suggest a positive impact on orphans, though are somewhat inconclusive (Strebel, 2004). This phenomenon should be examined in future studies, perhaps in qualitative work. Next, when comparing different types of orphans, we found that paternal orphans are at higher risk of not going to school in Burkina Faso, which is inconsistantly noted in other studies (e.g. see Manasch and Boerma 2004). As the issues surround orphanhood and also education reflect a complex mix of sociodemographic, policy, and individual variables, thus the analysis and detection of trends among orphans is important to monitor the impact community and national programs, and to identify unmet needs and social determinants or poor educational progress.

Acknowledgments: We would like to thank the Abbott Fund through the Axios Health Care Development for support of this study. We thank the communities and their leaders, and interviewers, for collaboration in the implementation of the mapping. We thank Alphonse Baltazar, Zaharani Kalungwa, Alfred Magalla and Clotaire Ouedraogo for organizing and implementing the field survey. 


\section{List of References}

Ainsworth, M., \& Semali, I. (2000). The impact of adult deaths on child health in Northwestern Tanzania. World Bank Policy Research Working Paper, No. 2266.

Ainsworth, M., \& Filmer, D. (2002). Poverty, AIDS and children schooling: A targeting dilemma. World Bank Policy Research Working Paper, No. 2885.

Bentaouett R. (2006) School Fees. Paper commissioned for the EFA Global Monitoring Report 2006, Literacy for Life. Report 2006/ED/EFA/MRT/PI/11/.

Bicego, G., Rutstein, S., \& Johnson, K. (2003). Dimensions of emerging orphans crisis in sub-Saharan Africa. Social Science \& Medicine, 56, 1235-1247.

Bishai, D., Brahmbhatt, H., Gray, R., Kigozi, G., Serwadda, D., Sewankambo, N., Suliman, E.D., Wabwire-Mangen, F., \& Wawer, M. (2003). Does biological relatedness affect survival? Demographic Research, 8(9), 261-278.

Bizé, M., \& Dye, T.D.V. Children' Education in Bobo-Dioulasso, Burkina Faso: is the orphan's status discriminating? To be submitted.

Case, A., Paxson, C., \& Ableidinger, J. (2003). The education of African orphans. Center for Health and Wellbeing. Research Program in Development Studies, Princeton University.

Foster, G., Williamson, J. (2000). A review of current literature on the impact of HIV/AIDS on children in sub-Saharan Africa. AIDS;14 (Suppl 3):S275S284.Lindblade, K.A., Odhiambo, F., Rosen, D.H., \& DeCock, K.M. (2003). Health and nutritional status of orphans $<6$ years old cared for by relatives in western Kenya. Tropical Medecine and International Health, 8, 67-72.

Gray PB (2004). HIV and Islam: Is HIV lower among Muslims? Social Science and Medicine, 58:1751-1756. 
Institut National de la Statistique et de la Démographie (INSD) et ORC Macro. 2004. Enquête Démographique et de Santé du Burkina Faso 2003. Calverton, Maryland, USA : INSD et ORC Macro.

Michigan State University. (1998-1999). The several forms of "Community Mapping" 1. Best Practice Briefs (3).

R. Monasch R, Stover J, Loudon M, Kabira D, Walker N. (2007). National response to orphans and other vulnerable children in sub-Saharan Africa: The OVC Policy and Planning Effort Index, 2004. Vulnerable Children and Youth Studies, 2:40-59.

National Bureau of Statistics (NBS) [Tanzania] and ORC Macro. 2005. Tanzania Demographic and Health Survey 2004-05. Dar es Salaam, Tanzania: National Bureau of Statistics and ORC Macro.

Nyamukapa C, Gregson S. (2005). Extended family's and women's roles in safeguarding orphans' education in AIDS-afflicted rural Zimbabwe. Social Science \& Medicine, 60, 2155-2167.

Orazem, P., \& Gunnarsson, V. (2003). Child labor school attendance and academic performance: a Review. International Labour Office.

Pagnier J., Kürzinger, M.L., Kahn, J.G., Hampshire, R., Dye, T.D.V. Education status among orphans and non orphans in two areas of Bobo-Dioulasso, Burkina Faso. Vulnerable Children and Youth Studies (in press).

Sengendo, J., \& Nambi, J. (1997). The psychological effect of orphanhood: A study of orphans in Rakai district (Uganda). Health Transition Review, 7 (suppl.), 105-124.

Strebel, A. (2004). The Development, Implementation and Evaluation of Interventions for the Care of Orphans and Vulnerable Children in Botswana, South 
Africa and Zimbabwe. A literature review of evidence-based interventions for homebased child-centred development. Human Sciences Research Council.

UNICEF. (2003). Africa's Orphaned Generations. New York..

UNICEF. (2006). Africa's Orphaned and Vulnerable Generations. Children affected by AIDS. New York.

UNICEF, UNAIDS, USAID. (2004). Children on the Brink: A joint report on new orphans estimates and a framework for action.

USAID. (2004). Understanding the needs of orphans and other children affected by HIV and AIDS in Africa. State of Science. Draft, April 2004. 
Table 1. Results of logistic Regression: Unadjusted Odds Ratio

\begin{tabular}{|c|c|c|c|c|c|c|}
\hline \multirow[t]{2}{*}{ For Burkina Faso } & \multicolumn{2}{|c|}{ Orphan } & \multicolumn{2}{|c|}{ Non orphan } & \multirow[b]{2}{*}{ OR } & \multirow[b]{2}{*}{$95 \% \mathrm{Cl}$} \\
\hline & (No.) & $(\%)$ & (No.) & $(\%)$ & & \\
\hline Not going to school & 502 & 64.77 & 2434 & 60.37 & 1.21 & $1.03,1.42$ \\
\hline Not being at proper educational level & 165 & 67.35 & 884 & 59.49 & 1.40 & $1.05,1.87$ \\
\hline \multirow[t]{2}{*}{ For Tanzania } & \multicolumn{2}{|c|}{ Orphan } & \multicolumn{2}{|c|}{ Non orphan } & & \\
\hline & (No.) & $(\%)$ & (No.) & (\%) & OR & $95 \% \mathrm{Cl}$ \\
\hline Not going to school & 407 & 27.26 & 945 & 27.62 & 0.98 & $0.86,1.12$ \\
\hline Not being at proper educational level & 924 & 85.48 & 2092 & 84.80 & 1.05 & $0.86,1.29$ \\
\hline
\end{tabular}

N.B. Non orphan $=$ Non orphan and non vulnerable 
Table 2. Results of Logistic Regression: Exponentiated log odds of a child being orphan, not going to school and not being at proper level in Burkina Faso

\begin{tabular}{|c|c|c|c|c|c|c|c|c|c|c|c|c|}
\hline & \multicolumn{4}{|c|}{ Being orphan } & \multicolumn{4}{|c|}{ Not going to school } & \multicolumn{4}{|c|}{ Not being at proper level at school } \\
\hline & (No.) & $(\%)$ & OR & $90 \% \mathrm{Cl}$ & (No.) & (\%) & OR & $90 \% \mathrm{Cl}$ & (No.) & (\%) & OR & $90 \% \mathrm{Cl}$ \\
\hline Total & 777 & 16.11 & & & 2942 & 61.06 & & & 1053 & 60.66 & & \\
\hline \multicolumn{13}{|l|}{ Age of the child } \\
\hline $6-11$ & 337 & 12.24 & Referent & & 1585 & 57.62 & Referent & & 465 & 42.78 & Referent & \\
\hline $12-18$ & 369 & 21.89 & 2.01 & $1.75,2.30$ & 1143 & 67.91 & 1.56 & $1.40,1.73$ & 463 & 94.88 & 24.78 & $17.41,35.24$ \\
\hline \multicolumn{13}{|l|}{ Sex of the child } \\
\hline Male & 407 & 16.40 & Referent & & 1461 & 58.89 & Referent & & 585 & 61.64 & Referent & \\
\hline Female & 369 & 15.79 & 0.96 & $0.84,1.09$ & 1477 & 63.34 & 1.21 & $1.09,1.33$ & 468 & 59.54 & 0.92 & $0.78,1.08$ \\
\hline \multicolumn{13}{|l|}{ Religion of the child } \\
\hline Muslim & 427 & 14.36 & Referent & & 2083 & 70.21 & Referent & & 465 & 57.62 & Referent & \\
\hline Christian & 338 & 19.05 & 1.40 & $1.23,1.60$ & 806 & 45.46 & 0.35 & $0.32,0.39$ & 576 & 63.65 & 1.29 & $1.09,1.52$ \\
\hline \multicolumn{13}{|l|}{ Sex of the head of household } \\
\hline Male & 519 & 11.76 & Referent & & 2702 & 61.30 & Referent & & 948 & 59.85 & Referent & \\
\hline Female & 254 & 66.32 & 14.78 & $12.17,17.93$ & 227 & 59.27 & 0.92 & $0.77,1.10$ & 99 & 71.22 & 1.66 & $1.21,2.28$ \\
\hline \multicolumn{13}{|l|}{ Family of origin } \\
\hline Yes & 555 & 12.56 & Referent & & 2676 & 60.64 & Referent & & 968 & 59.98 & Referent & \\
\hline No & 219 & 56.01 & 8.86 & $7.38,10.65$ & 256 & 65.64 & 1.24 & $1.03,1.49$ & 82 & 70.09 & 1.56 & $1.11,2.20$ \\
\hline \multicolumn{13}{|c|}{ Relationship of the child to the head of household } \\
\hline Grand-parents & 97 & 39.27 & Referent & & 138 & 55.87 & Referent & & 56 & 60.22 & Referent & \\
\hline Parents and other relatives & 677 & 14.87 & 0.27 & $0.22,0.34$ & 2792 & 61.42 & 1.26 & $1.01,1.56$ & 992 & 60.82 & 1.03 & $0.72,1.47$ \\
\hline \multicolumn{13}{|l|}{ Dependency ratio } \\
\hline$\leq 1$ & 197 & 17.59 & Referent & & 658 & 58.75 & Referent & & 257 & 61.19 & Referent & \\
\hline$>1$ & 580 & 15.67 & 0.87 & $0.75,1.01$ & 2282 & 61.74 & 1.13 & $1.01,1.27$ & 796 & 60.49 & 0.97 & $0.80,1.17$ \\
\hline
\end{tabular}


Table 3. Results of logistic Regression: Adjusted Odds Ratios in Burkina Faso

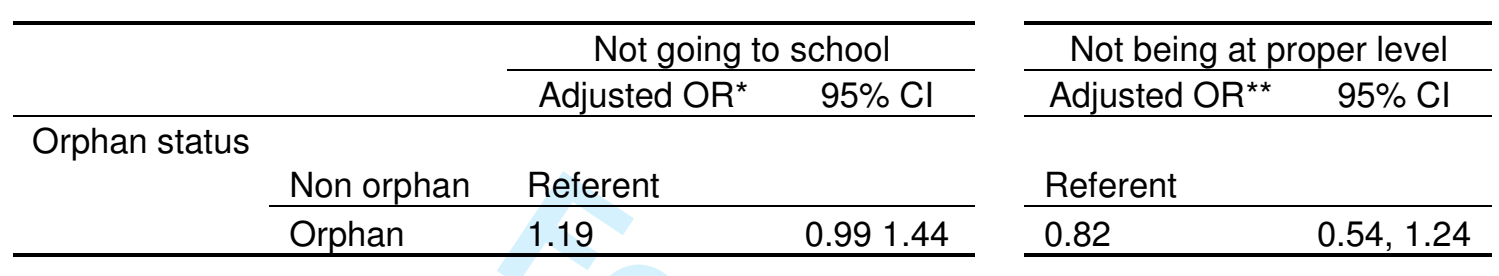

${ }^{*}$ ) adjusted for age, religion, family of origin, relation with the household head

$\left(^{* *}\right)$ adjusted for age, religion, family of origin, gender of the household head

N.B. Non orphan $=$ Non orphan and non vulnerable 